\title{
Problem-solving skills and suicidal ideation among Malaysian college students: the mediating role of hopelessness
}

\begin{abstract}
Objective: Recent evidence suggests that suicidal ideation has increased among Malaysian college students over the past two decades; therefore, it is essential to increase our knowledge concerning the etiology of suicidal ideation among Malaysian college students. This study was conducted to examine the relationships between problem-solving skills, hopelessness, and suicidal ideation among Malaysian college students. Methods: The participants included 500 undergraduate students from two Malaysian public universities who completed the selfreport questionnaires. Results: Structural equation modeling estimated that college students with poor problem-solving confidence, external personal control of emotion, and avoiding style were more likely to report suicidal ideation. Hopelessness partially mediated the relationship between problem-solving skills and suicidal ideation. Conclusion: These findings reinforce the importance of poor problem-solving skills and hopelessness as risk factors for suicidal ideation among college students.
\end{abstract}

Keyword: Hopelessness; Problem-solving skills; Psychological tests; Suicidal ideation 